\title{
ESTÁGIO ATUAL DAS PESQUISAS EM TELEADMINISTRAÇÃO ${ }^{1}{ }^{2}$
}

GIOVANNI DUNI*

Uma cordial saudação a todos os participantes do Seminário de Direito Administrativo Eletrônico, na Universidade Candido Mendes, de Campos, no Brasil. Uma saudação especial ao colega Marcus Vinícius Filgueiras, que há tempo me contactou acerca das pesquisas sobre teleadministração e com o qual há uma promessa recíproca de intercâmbios culturais.

Pediu-me para ater-me ao texto escrito para permitir a tradução do que direi. Aceito o convite e falarei, então, lentamente.

No breve tempo de que disponho, tentarei dar um quadro muito sintético do estado da arte desta pesquisa, iniciada em 1978, e que prossegue e se desenvolve com indicações sempre mais circunstanciais para aquelas Administrações Públicas que desejam dar um salto de qualidade no uso eficiente da informática e da telemática. $\mathrm{Na}$ última parte da exposição, darei indicações a quem quiser aprofundar-se na matéria. Temos uma página na internet, na qual estão reportadas as pesquisas, a didática regular e as atividades do doutorado (www.teleamministrazione.it).

Ao término mostraremos as suas páginas básicas.

A síntese à qual me limitarei será muito semelhante a um sumário. Será uma série de afirmações, que mereceria um comentário mais detido para o qual me falta tempo.

1 Conferência inaugural proferida por teleconferência no I Seminário Internacional de Direito Administrativo Eletrônico promovido pela Universidade Candido Mendes-Campos e pela Universidade de Estudos de Cagliari, Itália, realizado no dia 23 de março de 2004. em Campos (RJ).

2 Tradução autorizada de Marcus Vinícius Filgueiras Júnior.

* Professor Titular de Direito Administrativo da Faculdade de Direito da Universidade de Estudos de Cagliari, Itália; Diretor do Departamento de Direito Público e Estudos Sociais e Coordenador do Doutorado em Direito da Atividade Administrativa Informatizada e da Comunicação Pública, da mesma Universidade; e Presidente da Associazione Teleamministrazione. 
A idéia na base de toda a mudança revolucionária proposta no distante 1978 foi aquela de desmaterializar os atos jurídicos, isto é, de reconhecê-los válidos diretamente na forma eletrônica, com as adequadas garantias de autenticidade que o direito exige. Esta proposta inovadora não era estimulada por um instinto genérico para a inovação e para a modernidade a todo custo, mas por uma precisa constatação: nos fios da rede telemática não passam as cartas, mas somente as mensagens eletrônicas. Ademais, não havia muito sentido expedir uma mensagem velocíssima, uma mensagem eletrônica, se se precisa aguardar a chegada daquela no papel, como sendo a única válida. Essa informática que convive com os papéis foi por mim criticamente denominada de "informática paralela", expressão que hoje é bastante difundida.

Inicialmente, gostaria de destacar que a passagem do papel à forma eletrônica é um evento que entra na história da evolução da civilização do homem. Sabemos, todavia, que formas de comunicação precederam por anos e decênios a sua aceitação por parte do direito. As operações jurídicas são um pouco como as cerimônias religiosas, nas quais o rito termina por ser parte mesma do valor que se defende e que se quer conservar. É difícil alterar as coisas no campo jurídico e no religioso fez-se através dos séculos.

Assim, a escrita no direito superou pelo cansaço a oralidade. A escrita à mão foi superada pelo cansaço por aquela feita por meios mecânicos. A própria máquina de escrever foi acolhida na Itália pelas leis notariais somente na segunda metade do século XX. Em todas essas mudanças sempre houve uma fase de uso paralelo do novo com o velho. A forma escrita dos atos jurídicos era, antigamente, só a documentação dos atos que eram válidos com base na "palavra dada", ou seja, da oralidade (aqui o uso do escrito é como forma ad probationem). A constância com a qual vinha exigida a nova forma para os atos mais importantes levou a realidade a considerar que a escrita fosse a condição própria de existência desses atos (aqui a escrita tornou-se forma ad substantiam).

Nos últimos decênios, maiores dúvidas são colocadas em questão sobre a possibilidade de dar validade à forma eletrônica, sobre a causa da sua intangibilidade e do seu próprio desaparecimento, quando tem origem ligada apenas à memorização magnética. A facilidade de se apagar, intencional, por erros ou por defeitos, fazia . forma eletrônica parecer efêmera quase como a oralidade. Mas a segurança dos sistemas de memorização, que podem também ser plúrimos, e sobre suporte ótico não cancelável, têm chamado a atenção dos estudiosos do problema da conservação dos dados e aquele, mais importante do ponto de vista jurídico, da segura atribuição do ato ao seu autor.

O que há de particular nessa nova forma de comunicação? Quais os problemas que se põem para que possa tornar-se forma jurídica ad probationem e, sobretudo, ad substantiam? Alguns autores, a fim de acelerar a evolução, escreveram que a forma eletrônica era também uma forma escrita. A argumentação não era, no entanto, relevante porque daquele tempo até hoje se entende o ato escrito como ato subscrito. E certamente não pode ser subscrito o ato que reside no computador. Os desenhos digitais da assinatura, inseridos no final do documento, não conferem nenhuma garantia, pois qualquer pessoa poderá copiá-lo e inseri-lo ao final de outros escritos, 
com a finalidade de atribuir-lhe à pessoa que foi a autora daquele exemplar de assinatura desenhada.

Portanto, somos obrigados a percorrer outros caminhos. Mas aqui a tarefa do jurista se detém, pois nas regras de base da teleadministração está previsto que "a firma (eletrônica) consiste na identificação da identidade do operador por meio de técnicas sofisticadas", confiando, assim, o problema aos técnicos.

As soluções foram muitas. Hoje podem ser identificadas com:

- Qualquer coisa que se conhece (password);

- Qualquer coisa do próprio corpo: chaves biométricas (impressão digital, íris, e muitas outras);

- Qualquer coisa que se possua: esta última solução se divide em outras duas:

- Segundo a mais simples, possui-se um cartãozinho, que contém os códigos de identificação: na prática, uma password memorizada e que pode ser muito mais complexa do que aquela que de se recordar e digitar;

- A solução mais evoluída prevê, ao contrário, a posse da chave para se apor a firma digital.

Todas essas soluções podem ser utilizadas isoladamente ou combinadas para melhorar a segurança nas intervenções jurídicas de maior importância. Para as mais velhas soluções sabemos que o caixa eletrônico prevê seja o cartãozinho, seja a digitação da password.

De qualquer forma, todas as soluções dividem-se em duas categorias:

- Identificação de efeito momentâneo

- Identificação que se incorpora ao documento

Entre todas aquelas mencionadas, somente a firma digital se incorpora ao documento.

As consequiências desta diferença são muito importantes. A identificação momentânea (por exemplo, por meio da íris) garante que o operador é aquele que deve agir. Mas, de per si, a identificação momentânea impõe que o documento criado seja cuidadosamente guardado. Se o documento sai do sistema informativo da Administração Pública que o possui, perde todo o valor. As possíveis cópias possíveis são aquelas em papel, que um encarregado poderá certificar como "conforme o original" existente no sistema informativo da Administração Pública.

A firma digital, ao contrário, se incorpora ao documento e o segue em toda cópia que venha a ser feita. A tecnologia tem também resolvido outro problema de extrema importância no mundo do direito: aquele da datação. É possível que um 
ente habilitado certifique que a firma digital seja aposta em um determinado momento. Esta certificação se traduz na marcação temporal, que igualmente se incorpora ao documento.

Sobre estas soluções que a técnica colocou à disposição, o jurista não pode deixar de observar que a firma digital é seguramente superior às outras soluções. Password e biometria deixam o documento em permanente situação de perigo, relegada à imperfeita guarda da Administração Pública.

Mas a firma digital também contém defeito, qual seja aquele de ser relegada ao possuidor. Ela garante que quem emanou o ato possuía aquela chave para a firma digital, mas não garante que quem a usou tenha sido efetivamente o titular habilitado a usá-la. Pensemos nas hipóteses de desaparecimento, furto, consignação em confiança.

O ideal seria uma chave de firma digital que, para funcionar, exigisse uma confirmação biométrica da pessoa. Isto será possível para atos jurídicos de particular importância, pois se se pretendesse estender esses a todo esse sistema o custo revelar-se-ia excessivo. Na Itália se fala no objetivo de dotar todos os cidadãos de firma digital, eventualmente incorporada à carteira de identidade eletrônica. Para o cidadão comum será possível usar a firma digital, mas deverá dispensar muita atenção na sua guarda. A perda da chave da firma digital seria muito mais grave do que a perda do "bancomat" ou do cartão de crédito.

A Itália foi a primeira nação européia a adotar a solução da firma digital, com um regulamento de 1997. Mas a União Européia tem entendido necessário alterar a normativa, tornando-a menos rigorosa, distinguindo uma firma digital segura daquela do tipo comum.

Em comentário às últimas leis, posso dizer que, mesmo após cerca de 20 anos da idéia do valor jurídico da forma eletrônica, o legislador já desenhou o princípio base.

Todavia, a passagem da velha informática paralela à nova não se verificou ainda por causa de um importante esquecimento: partindo da premissa de que o ato administrativo em forma eletrônica seja válido, como se o produz?

Em toda esta minha exposição cometi um pequeno engano, ou melhor, falei com base numa simplificação irreal, ou seja, para simplificar o discurso, falei como se os atos administrativos fossem instruídos, valorados, controlados e decididos por uma só pessoa. Na realidade, todos os atos são fruto da atividade de mais órgãos no âmbito do procedimento administrativo. Os procedimentos administrativos mais importantes, entre outros, envolvem várias administrações separadas e autônomas.

Falta uma disciplina adequada para gerir esta complexa realidade. É necessário destacar fortemente que somente quando existir a disciplina do procedimento administrativo telemático se poderá produzir um ato administrativo eletrônico.

Hipoteticamente, verifica-se varias soluções: utilizar o correio eletrônico certificado, usar os "formulários on line" ... Mas não posso caminhar além dessa problemática, cuja abordagem demandaria muito tempo.

No momento das escolhas, é de se recordar que estas devem considerar o fato de que a complexidade administrativa não tem limites. À época do Jubileu, o prefeito de Roma observou que para uma intervenção urbanística eram necessárias 65 pas- 
sagens burocráticas. Mas era ainda pouco. Sabemos que para uma conferência de serviços relativa à metropolitana de Roma era preciso locar uma sala cinematográfica, pois deveriam intervir (acreditem!) 185 autoridades.

Concluo, assim, sem comentar, que estes dados indicam a importância das escolhas relativas ao tema dos procedimentos telemáticos. Com os presentes aqui em Cagliari poderemos abrir um debate.

Aos amigos brasileiros envio uma saudação especial cheia de calor latino, e desejo um bom trabalho no seminário sobre o Direito Administrativo Eletrônico. Obrigado. 


\section{Apontamentos sobre a Reforma Administrativa}

Diogo de Figueiredo Moreira Neto

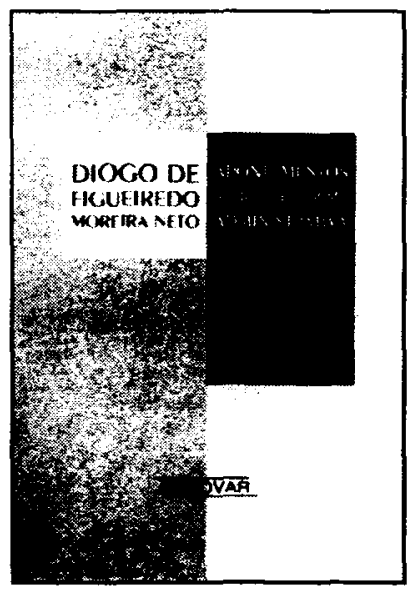

Este livro mantém-se introdutório e despretensioso, oferecendo apenas um guia de anotações, por entender que estas devam ser apenas um início e uma abertura de uma necessária e ponderável contribuição doutrinária e jurisprudencial que deverão amadurecer no estudo e no debate e haverão de ser fundamentais para sua serena e correta aplicação, não só em benefício do aperfeiçoamento como, e principalmente, da segurança jurídica.

Ref. 0214

Form. 14x21

Brochura

1999

182 págs.

\section{A Reconstrução dos Direitos Humanos da Tributação}

Nesta obra, o autor retorna à análise do fenômeno tributário, agora na vertente dos Direitos Humanos, a partir dos eventos que se seguiram à Revolução Francesa, elaborando uma inédita Teoria Geral da Tributação de profunda importância para a emancipação da Democracia.

Alberto Nogueira

Alberto Nogueira

Ref. 0143

Brochura

Form. 14x21

472 págs.

A RECONSTRUÇÃ0 DOS

DIREITOS HUMANOS

DA TRBUTC:

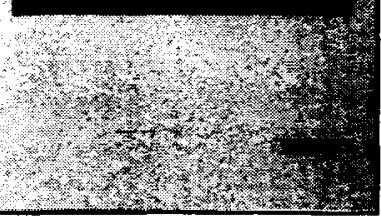

